\title{
Jornalismo de variedades: cartografia de uma especialidade da imprensa
}

\author{
Francisco de Assis*
}

\section{Resumo}

O artigo traça um panorama histórico e evolutivo dos referenciais existentes a respeito do jornalismo de variedades, tencionando ideias e aproximando os posicionamentos que mais se achegam à realidade do mercado. Seu principal objetivo é mais bem conceituar essa prática jornalística, que tem ganhado considerável espaço em jornais e em revistas, mas que ainda carece de balizamento teórico. A metodologia adotada resume-se à pesquisa bibliográfica. Com especial atenção ao cenário brasileiro, o texto revela as transformações provocadas na imprensa, desde o século 19, que culminaram na atual concepção que se pode ter do jornalismo de variedades: uma especialidade que se ocupa da cobertura sobre cultura e entretenimento, com enfoque nas opções de lazer que estão à disposição do público-leitor.

Palavras-chave: Jornalismo de variedades. Jornalismo especializado. Teoria do jornalismo. Cultura. Entretenimento.

\section{Variety Journalism: the mapping of a press specialty Abstract}

The article provides a historical and evolutionary overview on the references regarding variety journalism, confronting ideas and articulating stances that most resemble the market features. Its main goal is to better conceptualize this journalistic practice, which has been conquering significant space in newspapers and magazines, but that still lacks theoretical marking. The methodology is based on bibliographical research. With a special attention to the Brazilian scenery, the text unveils the changes shaped by the press, since the nineteenth century, that ended up on the current design of what may be considered variety journalism: a specialty that deals with arts and entertainment focusing on leisure options available to the readership.

Key words: Variety journalism. Specialized journalism. Journalism theory. Culture. Entertainment.

* Doutorando e Mestre em Comunicação Social e Especialista em Jornalismo Cultural pela Universidade Metodista de São Paulo (Umesp). Professor de cursos de pós-graduação (lato sensu) do Departamento de Comunicaçao / Pró-Reitoria de Pesquisa e Pós-Graduação (PRPPG) da Universidade de Taubaté (UNITAU) e pesquisador do Núcleo de Pesquisa e Estudos em Comunicação (Nupec), na mesma instituição. Taubaté-SP, Brasil. E-mail: francisco@assis.jor.br 


\section{Periodismo de variedades: la cartografía de una especialidad de prensa}

\section{Resumen}

El artículo proporciona una visión histórica y evolutiva de las referencias existentes sobre el periodismo de variedades, con la intención de exponer las ideas que se acercan más a la realidad del mercado. Su objetivo principal es describir mejor esta práctica periodística, que ha ganado un espacio considerable en los periódicos y en las revistas, pero que aún requiere organización teórica. La metodología se basa en la investigación bibliográfica. Con especial atención a la realidad brasileña, el texto pone de manifiesto los cambios producidos en la prensa desde el siglo 19, que culminaron en el diseño actual del periodismo de variedades: una especialidad que se ocupa de la cobertura de la cultura y del entretenimiento, centrándose en las opciones de ocio que están disponibles para los lectores.

Palabras clave: Periodismo de variedades. Periodismo especializado. Teoría del periodismo. Cultura. Entretenimiento.

\section{Introdução}

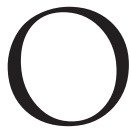

jornalismo de variedades tem se legitimado, cada vez mais, como especialidade destinada a cobrir pautas de cultura e entretenimento, com vistas a oferecer opções de lazer ao público dos veículos nos quais figura. Todavia, ainda necessita ser mais bem conceituado.

Essa necessidade se identifica pelo fato de as discussões existentes, a esse respeito, pautarem-se muito mais em desencontros de posicionamentos do que, propriamente, em observações em linha reta. Ao que parece, os autores que se propuseram a discorrer sobre a relação entre jornalismo e variedades não caminham num mesmo sentido, chegando a conclusões diferentes e, até mesmo, opostas.

$\mathrm{Na}$ tentativa de elucidar em que consiste tal prática, este artigo percorre pistas que sejam suficientes para delinear as fronteiras desse tipo de jornalismo especializado ${ }^{1}$. Desse modo, a problemática

\footnotetext{
${ }^{1}$ Neste texto, entende-se o jornalismo especializado de acordo com o que orienta Juarez Bahia (1990, p.214), ou seja, "uma necessidade social" que "resulta do próprio desenvolvimento das relações na sociedade". Trata-se, assim, de "uma técnica de tratamento da notícia que se aperfeiçoa paralelamente à evolução dos meios de produção, das tecnologias industriais e comerciais, das aquisições culturais, das pesquisas e experiências científicas". Ainda cabe lembrar que, para Mário Erbolato (1981, p.94), a cobertura especializada possui duas características: 1) primária, "que é parte inseparável dos veículos de assuntos gerais, como as seções (nos impressos) ou os programas (nos audiovisuais), e 2) autônoma, "que tem veiculação e periodicidade próprias, sejam de notícias, sejam de publicidade".
} 
que dá origem ao texto questiona o que as fontes de referência da área - celebradas ou da "literatura cinzenta" - consideram sobre a relação entre jornalismo e variedades. A abordagem, portanto, ancora-se em pesquisa bibliográfica.

\section{Jornalismo e variedades: diálogos de fronteira}

Mesmo ganhando considerável fôlego nos anos 2000, o fenômeno evocado neste texto não é nada novo. Como será visto nas linhas que seguem, as variedades, enquanto foco de cobertura jornalística, chegam ao Brasil no século 19. Contudo, elas só conseguem se legitimar na década de 1980, em razão de fatores socioculturais que delinearam a história da imprensa no país no último quartel do século 20. Não por acaso, as reflexões e os registros técnicos sobre tal temática só começam a eclodir naquele período. Ao menos, a maior parte delas.

Analisando a literatura da área, percebe-se que, no Brasil, o terreno do jornalismo de variedades começou a ser palmilhado no início da década de $1960^{2}$, por Luiz Beltrão (2006, p.121), que explicava as seções dessa natureza como sendo formadas por "notícias meteorológicas, fixação de efemérides, consultórios ou colunas de conselhos, passatempos, curiosidades e miscelâneas”, além de horóscopos, voltados para estudos astrológicos e para previsões sobre os signos do Zodíaco.

É curioso notar que alguns dos tópicos selecionados pelo autor - como passatempos e horóscopos, por exemplo - não constituem gêneros e formatos jornalísticos, mas, sim, "gêneros do jornal"3. Os demais coincidem, de certo, com a "função lúdica" do jornalismo,

\footnotetext{
${ }^{2} \mathrm{O}$ texto de Beltrão, elaborado inicialmente como material didático para as aulas que ministrava no curso de Jornalismo da Universidade Católica de Pernambuco, foi republicado em 2006, sob o título Teoria e prática do jornalismo, pela Cátedra Unesco/Metodista de Comunicação para o Desenvolvimento Regional, em parceria com as Faculdades Adamantinenses Integradas (FAI). Vale observar que, em seu texto, o autor não utiliza a nomenclatura "jornalismo de variedades", referindo-se tão-somente a "seções de variedades" como componentes dos jornais impressos. ${ }^{3}$ Os gêneros do jornal são as espécies que compõem uma publicação impressa, mas que não necessariamente se constituem como material jornalístico.
} 
que se configura como "um meio de fuga às preocupações do quotidiano ou costumeiro, uma pausa no ramerrão, um preenchimento dos lazeres com algo reparador do dispêndio de energias reclamado pela atividade vital de informar-se" (BELTRÃO, 1980, p.13).

Num de seus estudos seminais, no qual analisa o conteúdo de jornais brasileiros publicados no final da década de 1960, José Marques de Melo (1972, p.98) coloca as variedades ao lado das histórias em quadrinhos, submetendo ambas à categoria "entretenimento". Sem se estender no assunto, o autor apenas aponta quais são seus componentes: as palavras cruzadas, o horóscopo, as charadas e as curiosidades. Deixa a entender, assim, que não se trata de conteúdo jornalístico.

As variedades aparecem, ainda, na obra de Mário Erbolato (1981, p.93-112), em capítulo dedicado a elas e aos suplementos. Ao tratar das especialidades do jornalismo, o autor assinala 18 tipos de conteúdos que compõem editorias dessa natureza, as quais se constituem num misto de textos intrínsecos ao jornalismo cultural - como crítica de cinema, crítica literária e crítica de televisão e de rádio - e de outros temas que supostamente não encontrariam lugar nas editorias clássicas dos jornais, como turismo, assuntos agrícolas, assuntos femininos, suplementos infantis, automobilismo, efemérides e rememorações, curiosidades, tempo, horóscopos, filatelia, numismática, orientações para o lazer, cinofilia, profissões e atividades e histórias em quadrinhos.

Cremilda Medina (1988, p.77) também se refere a "colunas e críticas de variedades” - relacionadas a artes e espetáculos - que revelam "vestígios expressos da personalidade da mensagem”, mas com pouca "individualidade de expressão", pelo fato de os responsáveis por sua elaboração geralmente estarem ligados a grupos de interesse, como "intelectuais", "determinada classe social”, "grupos religiosos", entre outros. "Na maior parte dos casos, são porta-vozes. Se tomarmos um caso crítico, como o colunista de livros, é bem mais frequente que ele faça press-release das obras selecionadas para divulgar, do que uma crítica ou resenha crítica”. As colocações da autora remetem, pois, à compreensão das variedades como espaço para a divulgação de produtos da indústria cultural. 
Os trabalhos de Beltrão e de Erbolato - entendidos como as primeiras reflexões nacionais a respeito do tema abordado ${ }^{4}$ - têm algo em comum: além do fato - já citado - de não classificarem apenas os conteúdos jornalísticos como variedades ${ }^{5}$, as pistas lançadas pelos autores evidenciam que o papel dessa especialidade está na promoção do entretenimento, com vistas a preencher os jornais com conteúdos mais amenos. Tal configuração é característica do jornalismo praticado na atualidade, momento em que se espera, como destaca Ignacio Ramonet (1999, p.137), que as informações trabalhadas pela imprensa sejam "fáceis, rápidas e divertidas".

As novas demandas do jornalismo refletem, evidentemente, uma evolução. Ao longo de quatro séculos ${ }^{6}$, essa atividade se modificou em escala considerável, conforme o despontar de novas tecnologias e em decorrência de transformações no cenário social. Para Ciro Marcondes Filho (2002, p.31), a produção jornalística mundial transitou por, pelo menos, cinco fases ${ }^{7}$; a última delas, a do “quarto jornalismo", iniciada por volta da década de 1970 e vigente até os dias de hoje, é caracterizada pela informação eletrônica e

\footnotetext{
${ }^{4}$ Aqui, não se faz mais alusão à obra de Marques de Melo (1972) por entender que, embora tenha apontado as variedades como item que figurava nos jornais da década de 1960, o autor não oferece pistas para uma imersão mais aprofundada no assunto, diferentemente do que fizeram Beltrão e Erbolato.

${ }^{5}$ Vale acrescentar que o mesmo equívoco é cometido por Dulcília Buitoni (1981, p.2), que, mesmo não utilizando o termo variedades, diz que o jornalismo diversional "engloba efemérides, palavras cruzadas, quadrinhos etc.".

${ }^{6}$ Comunga-se, neste artigo, do posicionamento de Marques de Melo (2003, p.48), para quem o jornalismo só teve início com a produção de jornais tipograficamente confeccionados, no século 17.

${ }^{7}$ Em síntese, as quatro primeiras fases a que Marcondes Filho (2002) se refere são as que seguem: 1) "pré-história do jornalismo" (1631-1789), caracterizada por uma economia elementar, produção artesanal e forma semelhante ao livro; 2) "primeiro jornalismo" (1789-1830), assinalado por conteúdos literários e políticos, com textos críticos, economia deficitária e comando a cargo de escritores, políticos e intelectuais; 3) "segundo jornalismo" (1830-1900), chamado de imprensa de massa, marca o início da profissionalização dos jornalistas, a criação de reportagens e manchetes, a utilização da publicidade e a consolidação da economia das empresas jornalísticas, e 4) "terceiro jornalismo" (1900-1960), considerado como imprensa monopolista, marcado por grandes tiragens de jornais, influência das relações públicas, grandes rubricas políticas e fortes grupos editoriais monopolizando o mercado.
} 
interativa, com ampla utilização da tecnologia, pela supervalorização de imagens e pelas mudanças nas rotinas dos jornalistas, as quais provocaram, como consequência, alterações no conteúdo produzido por esses profissionais. Hoje, segundo o autor, "assuntos associados ao curioso, ao insólito, ao imageticamente impressionante ganham mais espaço no noticiário"; logo, o público deixa de "informar-se sobre o mundo" para "surpreender-se com pessoas e coisas".

No rastro dessas novas demandas, as seções de variedades já são compreendidas como produção associada à editoria de cultura. $\mathrm{Na}$ visão de alguns pesquisadores, esse é um processo de redução do campo cultural - isto é, do espaço de veiculação de ideias, de críticas e de imersões mais aprofundadas nos assuntos ligados à cultura (FARO, 2007, p.76-80) -, em detrimento do aumento significativo de espaços voltados para diversão e passatempo (GADINI, 2007, online). Tais leituras, embora tendam a situar o jornalismo cultural num momento de "crise" (COUTO, 1996, p.129), oferecem contributos para o entendimento do jornalismo variedades.

\section{Transformações no jornalismo cultural}

Não existe, ao certo, uma data que demarque o início preciso do jornalismo especializado em cultura, mas é bem provável que sua origem esteja nas primeiras publicações jornalísticas que circularam pela Europa no século 17. Ana Luiza Martins (2001, p.38-39) diz que um dos primeiros jornais especializados de que se tem notícia é o semanário Journal des Sçavans, transformado, posteriormente, em Journal des Savants. Fundado em Paris, no ano de 1665, por Denys Sallo (1626-1669), é considerado o pioneiro do "periodismo literário", no qual está enraizado aquilo que se convencionou chamar de "jornalismo cultural".

Todavia, Daniel Piza (2007, p.11) defende que a revista diária The Spectator, fundada em Londres, em 1711, pelos ensaístas ingleses Richard Steele (1972-1729) e Joseph Addison (1672-1719), é a que melhor pode demarcar os "princípios" da especialidade em foco, pois já naquela ocasião apresentava muitas das características que perduraram ao longo dos séculos. Conforme relata o autor, aquela publicação abordava assuntos variados - como livros, óperas, costumes, festivais, política, entre outros - sempre em tom informal, embora reflexivo. 
Independentemente das controvérsias a respeito dos primeiros veículos jornalísticos especializados em cultura, é importante notar um ponto fundamental para o entendimento de sua formação: esse tipo de jornalismo emergiu como modelo de avaliação de ideias, valores e artes; em outras palavras, suas bases se ancoram na reflexão e na crítica cultural, mesmo que se observe, logo em seus primórdios - pelo exemplo apresentado por Piza -, tentativas de transformar esse exercício intelectual em algo divertido.

Ao longo da trajetória da imprensa, a crítica à literatura (especialmente), ao teatro, à música e às artes plásticas ocupou considerável espaço nos jornais. Maria Cecília Garcia (2004, p.108109) afirma que, no Brasil ${ }^{8}$, a crítica "até o início do século 20 era feita em profundidade” e, geralmente, era apreciada pelo público conhecedor de obras artísticas, o que "exigia do crítico um apuro maior nas análises, um conhecimento em profundidade da arte que estava criticando, se quisesse agradar ou fazer sentido para um leitor que conhecia o assunto”. Tornaram-se comuns, então, os rodapés e os suplementos literários, que se ocupavam de tais conteúdos; com o passar do tempo, no entanto, esse exercício crítico foi abrindo espaço para outra atividade: a resenha - o review anglo-saxão (JANUÁRIO, 2005, p.23) -, que se constitui muito mais como um registro do que há de novo no mercado editorial do que como um julgamento a seu respeito.

Como ressalta Marelo Januário (2005, p.20), "as transformações experimentadas pela arte na sociedade moderna se refletiram não apenas na sua produção, mas também na sua apreciação". Não por acaso, J. S. Faro (2007, p.76-77) considera que, ao obedecer às "regras do mercado e com os olhos voltados para o consumo dos bens culturais em todas as suas manifestações”, o jornalismo dedicado a esse segmento deixou, em larga medida, de cumprir com sua função original. "O que antes era espaço de atuação livre de vanguardas, de intelectuais e de críticos que marcavam sua presença nas páginas dos suplementos com interpretações de larga repercussão pública [...] agora não é mais que espaço de serviços voltado para o entretenimento".

As constatações de Sérgio Luiz Gadini (2007, online) também se voltam para esse lado. O autor observa que a "tendência de ex-

\footnotetext{
${ }^{8}$ Segundo Piza (2007, p.16), o jornalismo cultural brasileiro só ganhou força no final do século 19 , com as críticas literárias.
} 
plorar a cultura como um quase sinônimo de lazer e divertimento", com foco nos "setores de baixo poder aquisitivo", é reflexo dos fenômenos de massificação, que culminaram numa "era marcada pela celeridade da informação, consenso generalizado, queda da sensibilidade estética, hegemonia da programação televisiva, dentre outros fatores". Já Herom Vargas (2004, p.22) mostra que essas mudanças alteraram, inclusive, a própria noção de cultura adotada pelo jornalismo, que elevou "ao patamar de pautas culturais" temas como arquitetura, design, gastronomia e comportamento.

Grande parte das considerações feitas em torno do jornalismo especializado em cultura costuma ser, em certo sentido, pessimista. José Geraldo Couto (1996, p.129), por exemplo, afirma que, "no novo contexto criado a partir desse conjunto de mudanças" - leia-se: rápida modernização dos jornais e acelerada transformação do mercado de produtos culturais -, "o jornalismo cultural ainda não encontrou o seu espaço e a sua voz"; Evaldo Mocarzel (2001, p.128) considera que esse jornalismo, nas últimas décadas, "passou por um processo de empobrecimento e banalização que acabou contaminando a maior parte dos cadernos de cultura do país”, e Piza (2007, p.53) diz que "os cadernos diários [de cultura] estão mais e mais superficiais".

Quem parte de perspectiva oposta é Dulcília Buitoni (2000, p.56), que assegura ser possível encontrar um trabalho bem feito e até mesmo aquele exercício crítico há pouco mencionado - em vários formatos e em veículos de diferentes naturezas, até mesmo em "roteiros culturais da televisão aberta ou a cabo" ou em "reportagens ou seções de revistas para adolescentes". Segundo ela, há "diversidade e diversidades. Objetos múltiplos, imensos e pequenos públicos, públicos pasteurizados e públicos diferenciados, o jornalismo cultural é múltiplo e se multiplica”. Faro (2006, p.149) tenta, ainda, equilibrar a situação, trabalhando com a hipótese de que, atualmente, "o jornalismo cultural constitui-se em um território de práticas jornalísticas que tanto reiteram os signos, valores e procedimentos da cultura de massa quanto discursos que revelam tensões contra-hegemônicas características de conjunturas históricas específicas".

Apesar de também perceber que o modelo desse jornalismo especializado tornou-se o "modelo determinado pela indústria cultural”, Zuenir Ventura (1989, p.103) não enxerga o fenômeno 
com olhar apocalíptico. Ao contrário, defende que a redução no espaço dos jornais destinado à avaliação crítica dos bens simbólicos não impede que o jornalista faça um texto adequado, dentro dos padrões que se espera. "Não é porque se tem 40, 50, 60 ou 100 linhas que a resenha tem que necessariamente ser ruim ou superficial. Há resenhas e resenhas".

Na concepção de Jorge Rivera (1995, p.19, tradução nossa), todo jornalismo é um fenômeno cultural, em sua essência, independentemente do tema em pauta ou da maneira com que esse tema seja abordado. Porém, ele não deixa de perceber que, historicamente, o nome "jornalismo cultural" foi consagrado como uma "zona muito complexa e heterogênea da mídia”, que aborda os terrenos das "belas artes', das 'belas letras', das correntes do pensamento, das ciências sociais e humanas, da chamada cultura popular e de muitos outros aspectos que têm a ver com a produção, a circulação e o consumo de bens simbólicos, sem importar sua origem ou destino”. O autor ainda considera que os assuntos de incumbência do jornalismo cultural variam conforme o público que se deseja atingir, o qual pode ser consumidor de "cultura superior", de "cultura média" ou de "cultura baixa” (RIVERA, 1995, p. 29-30, tradução nossa).

\section{Cultura, entretenimento, variedades}

Na percepção de Marques de Melo (2009b, p.23-24), o jornalismo cultural brasileiro é uma categoria que emergiu nos anos 1980, como sucessora do jornalismo literário9 ${ }^{9}$, principal respon-

\footnotetext{
${ }^{9}$ É bom explicar que o jornalismo literário ao qual o autor se refere não corresponde às discussões feitas atualmente a respeito do jornalismo originado a partir do movimento norte-americano denominado New Journalism, que eclodiu nos EUA, em meados do século 20. A essa categoria, que tem como característica o texto escrito com recursos narrativos comuns à ficção e cujo mote deu brechas para a criação de uma Academia Brasileira de Jornalismo Literário (ABJL), Marques de Melo (2009a, p.4) prefere chamar de jornalismo diversional. $\mathrm{O}$ jornalismo literário mencionado por ele tem origem francesa e é caracterizado por relatos sobre movimentos acadêmicos, por textos educativos e pela própria reprodução de materiais elaborados por literatos. Trata-se, portanto, de um jornalismo sobre literatura. "Nesse sentido, os nossos pioneiros jornais literários constituem território livre para a publicação de textos de suporte cultural, em uma época em que o livro ainda não tinha logrado desenvolvimento satisfatório no País” (MARQUES DE MELO, 2009b, p.23).
} 
sável pela disseminação das críticas culturais, durante a primeira metade do século 20. A década à qual o autor se refere coincide, evidentemente, com o período de grandes transformações políticas e socioculturais pelo qual o país passou, durante seu processo de redemocratização. Naquela época, "o declínio ou desaparecimento dos suplementos dirigidos pelos grandes intelectuais dá lugar ao surgimento dos cadernos de variedades que atendem às demandas de consumo cultural das classes médias". O autor diz ainda que esse "novo" tipo de jornalismo cultural "refletiu a assimilação dos conceitos de 'indústria cultural' ou de 'cultura de massa”".

O trabalho da imprensa condicionado às camadas sociais ("classe média” e "elite”) é identificado por Daniel Piza (2007, p.52-53) como responsável pela sensível diferente entre os cadernos de jornais diários - "ditos de 'variedades' ou 'artes e espetáculos”, mais "superficiais" - e os "suplementos semanais, mais focados em livros, também em artigos sobre ciência ou textos longos sobre cultura em geral".

A "superficialidade" que parece predominar nos cadernos diários resulta, de acordo com Piza (2007, p.53), da supervalorização de entrevistas banais com celebridades; da restrição de conteúdos opinativos na mancha gráfica dos jornais; do pouco espaço que se dá a colunistas especializados em arte e/ou de "jornalistas de carreira", e do grande espaço reservado para as reportagens, "que na verdade são apresentações de eventos", uma espécie de versão ampliada de releases produzidos por assessorias de imprensa. "Os assuntos preferidos, por extensão, são o cinema americano, a TV brasileira e a música pop, que dominam as tabelas de consumo cultural”.

Essa avaliação do autor ainda se estende aos cadernos semanais, em geral destinados a um conteúdo reflexivo, mas que estão presos a resenhas elaboradas por professores universitários e a temas ligados à ideia de erudição. "É possível, primeiro, falar sobre esses nomes e temas com um tratamento menos pomposo e insosso e, segundo, partir para outras faixas de repertório cultural, incluindo áreas de grande interesse popular, como o futebol e a televisão, num tratamento diferenciado" (PIZA, 2007, p.53).

Os denominados "segundos cadernos" seriam, portanto, os que praticam o jornalismo de variedades, diferenciando-se dos suplementos de final de semana, que se ocupam dos olhares críticos 
a respeito dos sistemas culturais - tornando-se um "suporte de disseminação de suas interpretações sobre o país, em boa parte dos casos transbordando para questões de ordem sociopolítica" (FARO, 2007, p.79) - e ainda abrem espaço para pautas que não se prendem à proximidade de um lançamento ou de uma estreia. As editorias diárias, por conseguinte, apenas divulgam aquilo que está à disposição no mercado cultural ou informam as opções de lazer.

Refletindo sobre as transformações ocorridas no jornalismo cultural brasileiro durante o final do século 20, Januário (2005, p.192) também afirma que a subordinação da imprensa às exigências do mercado sinaliza um período marcado pela superficialidade. "Prenunciando os novos tempos, os críticos eram agora jornalistas e especialistas, que privilegiaram em seus textos o mundo fashion de eventos e personalidades artísticas". No entanto, o autor revela que a "imprensa de variedades" no Brasil teve origem num período pretérito, mais precisamente no século 19, quando os jornais começaram a criar suplementos com periodicidade regular, inspirados nos folhetins ${ }^{10}$; ou, antes disso, é bom lembrar que a primeira revista a circular no país, em 1812, carregava como título As Variedades ou Ensaios de Literatura.

Muito embora tenha sido no século 19 que as variedades apareceram na imprensa brasileira, tem-se que foi durante o século 20 que elas conquistaram maior espaço. Um dos fatores mais evidentes - que condiz com o panorama evolutivo da mídia impressa - é a valorização das ilustrações, que se ajustaram perfeitamente aos conteúdos de entretenimento, conferindo a eles uma linguagem

${ }^{10}$ No século 19 , o folhetim fazia grande sucesso pelo mundo, inclusive entre os moradores do Brasil imperial. Sua origem - que pode ser associada à própria gênese das variedades - remonta à França do século mencionado, mais precisamente a 1836, ano em que o jornalista Émile Girardin concebeu um jornal barato, com inserção de reclames (anúncios publicitários) e com a utilização de um espaço, na mancha gráfica, que, desde o século 18 , já era reservado para o entretenimento: o rodapé - chamado também de variétés -, "espécie de almanaque integrado ao jornal, dedicado às variedades, [às] miscelâneas, ou às resenhas literárias, dramáticas ou artísticas" (MEYER; DIAS, 1984, p.35). Girardin solicitou a alguns romancistas que escrevessem histórias para serem publicadas em capítulos; deu início, assim, ao folhetim-romance, chamado mais tarde de romance-folhetim até reduzir-se à expressão mais comum e até hoje utilizada: folhetim. 
acessível ao público não muito habituado à leitura. Como assegura Heloisa de Faria Cruz (2000, p.112), "com a incorporação da linguagem fotográfica, a imprensa de variedades firma-se como gênero”.

Além de corresponderem às mudanças ocorridas em jornais e revistas, o jornalismo de variedades também acompanhou o desenvolvimento nacional. Sérgio Gadini (2003, p.54-55) considera que o "gradual surgimento da editoria" está ligado ao crescimento no índice de alfabetizados e à penetração da indústria cultural no país - principalmente com a ascensão do cinema e com a proliferação do rádio -, mas, por outro lado, também reflete o papel predominante de dona de casa que, na década de 1930, era atribuído à mulher, principal público atingido, até então, pelas seções aqui destacadas. Desse modo, a editoria em questão tentava "responder a uma demanda de novos leitores", atrelando-se à "noção de futilidades - ou seja, de que a cultura estava ou poderia estar associada a certas levezas ou curiosidades da vida privada" que despertavam "interesse público" (GADINI, 2003, p.54).

Naquele período, os suplementos culturais, "basicamente literários", que circulavam aos finais de semana, eram destinados à elite intelectual - formada, em sua quase totalidade, pelos homens -, enquanto as páginas de variedades eram voltadas para o público feminino, condicionado aos "afazeres do lar". "Aliás, é possível pensar que é também dessa relação a proliferação da já existente noção de variedades como sinônimo de 'amenidades', associado à tradição de jornais que sobrevivem da ostentação de colunáveis" (GADINI, 2003, p.78).

De volta à tentativa de organizar os referenciais que se dedicam aos aspectos que caracterizam esse objeto na contemporaneidade, cumpre mencionar outro olhar lançado por Gadini (2007, online): em sua análise, não são os conteúdos jornalísticos que, hoje, podem ser considerados como variedades, mas, sim, os demais elementos que servem para atrair o interesse do leitor e para suavizar a leitura de assuntos mais densos, tais como "horóscopo, palavras cruzadas, jogo dos sete (ou oito) erros e algumas tiras". O posicionamento do autor não difere totalmente do panorama indicado, décadas atrás, por Luiz Beltrão e por Mário Erbolato; a diferença está no fato de ele não misturar, num mesmo conceito, a especialidade do 
jornalismo com os demais itens publicados pelos jornais, o que, em certa medida, corresponde às primeiras observações empíricas feitas por Marques de Melo (1972).

Como complemento aos exemplos já apontados, cabe acrescentar que, de acordo com Gadini (2007, online), "o espaço das 'variedades' nos cadernos culturais dos diários brasileiros" é formado por “outras modalidades de 'entretenimento' e atividades afins, como numerologia, tarô, búzios, o anjo do dia, além de piadas, jogos e outras modalidades de diversão ou lazer”, também colocadas à parte da dimensão jornalística ${ }^{11}$. Citando uma jornalista que foi entrevistada durante sua pesquisa, o autor afirma que "a lógica das variedades que integra os cadernos culturais dos diários brasileiros segue, de modo geral, a perspectiva de 'entretenimento' do leitor, procurando 'deixar as páginas da editoria de cultura mais leves e atraentes ao interesse do leitor médio' [...]”. Não foge, desse modo, às regras estabelecidas em sua origem.

\section{Outras perspectivas}

Em verbete do Dicionário de Comunicação, as variedades constam como sinônimo exclusivo de programação veiculada em rádios e TVs. Esses programas são concebidos "em formato de competição, em que os participantes selecionados são celebridades ou membros da audiência [...] ou uma combinação de ambas, que competem entre si, com a plateia ou com o público de casa, de acordo com regras pré-estabelecidas, por algum tipo de recompensa" (RABAÇA; BARBOSA, 2001, p.749).

Do mesmo modo, Daniela Jesus Almeida (2004, p.71) localiza as variedades nos programas televisivos de auditório. Embora mostre que as grades dessa natureza se configuram, hegemonicamente, por quadros divertidos e, em certo ponto, sensacionalistas, a autora compreende que, muitas delas, já somam o jornalismo aos demais

\footnotetext{
${ }^{11}$ Gadini (2007, online) ainda coloca que, nos jornais diários, o espaço ocupado pelos recursos que ele denomina variedades é de $10 \%$ a $15 \%$ da mancha gráfica das editorias especializadas.
} 
conteúdos: "Percebe-se [...] que a inserção do jornalismo em um programa de auditório funciona como uma forma de diferenciação entre os vários programas exibidos do mesmo gênero e também como mais uma opção de se obter audiência”.

José Carlos Aronchi de Souza (2004) e André Barbosa Filho (2003) também separam as variedades - na TV e no rádio, respectivamente - do plano jornalístico. Ao menos, em parte, uma vez que ambos percebem a informação de atualidade como componente essencial dessas atrações. O primeiro desses autores - com o mesmo posicionamento de Almeida (2004) e de Rabaça e Barbosa (2001) - inclui os programas de variedades como componente do gênero televisivo "entretenimento"; em sua leitura, trata-se de programas estruturados aos moldes do formato revista ${ }^{12}$, mas que incluem elementos de outra natureza, como a programação de auditório - já mencionada - e o improviso, além do "grotesco" e do "bizarro", ingredientes que fazem o telespectador rir e chorar "com tudo que é apresentado" (ARONCHI DE SOUZA, 2004, p.193).

Barbosa Filho (2003, p.139), por sua vez, submete as variedades ao gênero radiofônico "especial" 13 , por considerar que elas não exercem especificamente a função jornalística, ou seja, que seu foco principal não está na informação e na análise dos fatos:

\footnotetext{
${ }^{12}$ Aronchi de Souza (2004, p.130) classifica o formato revista como componente do gênero entretenimento, afirmando o seguinte: "Nos programas do gênero revista pode haver vários formatos: telejornalismo, quadros humorísticos, musicais, reportagens, enfim, assuntos diversos como os enfocados por revistas impressas. A formatação do gênero revista é muito parecida com a dos programas de jornalismo e variedades, tendo como diferencial a postura mais comprometida com a categoria informativa do que com a de entretenimento. Nesse aspecto, o infortenimento - a informação unida ao entretenimento - passa a ser a linguagem utilizada para atrair a audiência. A notícia torna-se espetáculo e faz parte de uma espécie de show de informações".

13 Barbosa Filho (2003, p.138) chama de gênero especial aquele "que não possui [...] função específica como os dos outros gêneros, mas, sim, apresenta várias funções concomitantes". Ele ainda explica que "a este formato híbrido resolvemos atribuir para efeito classificatório a terminologia especial, incluindo-o num gênero multifuncional". Com relação aos programas de variedades, o autor ainda acrescenta que estes nasceram como programas musicais que, aos poucos, foram incorporando outras atrações artísticas e culturais até aglutinarem informações jornalísticas.
} 
"Conhecidos como radiorrevistas ou miscelâneas, os programas de variedades têm essa denominação pela multiplicidade de informações com características diferenciadas que apresentam em seus roteiros". Mais adiante, todavia, não deixa de apontar que, na atualidade, programas radiofônicos de variedades podem ser entendidos como "informativos que mesclam jornalismo e prestação de serviço com uma pitada de entretenimento e cultura" (BARBOSA FILHO, 2003, p.144).

Ainda com relação às variedades no rádio, parece comum a ideia de concebê-las como gênero autônomo, ligado ao entretenimento, mas que necessariamente precisa incorporar conteúdos jornalísticos. Para Gisela Ortriwano (1985, p.94), o programa dessa natureza, mesmo sem estar ligado essencialmente à atualidade, "pode conter a informação de interesse presumível para o público a que se destina, intercalada entre música, humor etc.”. Sua estrutura, então, inclui entrevistas, prestação de serviços, participação de ouvintes, entre outras atrações. Por outro lado, Robert Mcleish (2001, p.141) afirma que a ênfase dos programas de variedades está no conteúdo, o qual pode se tornar "maçante ou trivial quando degenera num amontoado de matérias frouxamente ligadas entre si”; a preocupação dos produtores, portanto, deve ser a de manter um estilo e apresentar "um conteúdo diferente e atualizado", além daquilo que o autor chama de "elemento surpresa" ${ }^{14}$.

Na coletânea que Norma Alcântara, Manuel Carlos Chaparro e Wilson Garcia (2005, p.317-335) organizaram, com entrevistas concedidas por jornalistas brasileiros a respeito de questões ligadas à imprensa, as variedades também são tema de um dos capítulos ${ }^{15}$. Os assuntos ali tratados relacionam-se a coberturas jornalísticas em torno de governo e cultura, indústria cultural, livros, cinema, música, bares e restaurantes, arte, patrocínio cultural, estrelismo,

${ }^{14}$ O "elemento surpresa" corresponde, segundo Mcleish (2001), a conteúdos de diferentes naturezas - inclusive informações jornalísticas -, inseridos na programação de modo a impedir que esta se torne previsível e cansativa.

${ }^{15}$ Trata-se do Capítulo 11 daquela coletânea, que tem como título "Cultura, variedades, entretenimento, sociedade e colunismo social”. 
eventos sociais, entre outros assuntos. Embora nenhum dos profissionais que responderam às perguntas daquela unidade tenha utilizado a expressão "variedades", em suas respostas, as palavras do jornalista Rodrigo Pereira - um desses colaboradores - apresentam um ponto que muito tem em comum com o mote da discussão aqui promovida. Conforme suas observações, "aquilo a que normalmente se chama 'jornalismo cultural' seria melhor definido como 'jornalismo sobre a indústria cultural'. Via de regra, nosso objeto é o novo sob a forma de produto" (ALCÂNTARA; CHAPARRO; GARCIA, 2005, p.321).

Articulista da Folha de S.Paulo, Bia Abramo (2005, online) é uma das poucas que utilizam a expressão "jornalismo de variedades", e o faz para se referir aos programas televisivos que combinam "jornalismo sério" e "entretenimento" ou "assuntos leves”. Tendo o claro interesse de avaliar as possibilidades de se fazer um trabalho "decente" nesse segmento e tomando como parâmetro o programa "Tudo a ver", apresentado por Paulo Henrique Amorim, na TV Record, ela afirma que a "opção editorial pela variedade comporta riscos, mas também é uma aposta que pode apontar para uma maneira de combater tanto a superficialidade extrema dos programas de fofoca como a brutalidade dos programas mundo-cão". E prossegue: "a idéia da variedade na pauta traduz-se em descontração (mas verdadeira, não afetada) no modo de apresentar, numa certa leveza da edição e no ar de conversa interessante".

O mesmo termo também é adotado por Ana Maria Gottardi e Semíramis Nahes (2006, p.196), ao se referirem à revista feminina Fon-Fon, publicada no Brasil de 1907 a 1958. Na avaliação das autoras, esse tipo de jornalismo é característico das publicações que combinam "generalidades" com "entretenimento" e que foram "transformadas em tendência", capazes de ditar moda. "Lazer, recreação, entretenimento, moda, humor, vida familiar, presse $d u$ coeur, estão, agora, profundamente ligados ao cotidiano de uma sociedade burguesa, segura de seus valores ainda recentes, e conseqüência da revolução industrial em curso no país”. Gottardi e Nahes explicam, ainda, que o jornalismo de variedades praticado por Fon-Fon ora era prestador de serviços - nas seções "Culinária 
de Bom Gosto", "Conselhos às Mães", "Página do Lar" -, ora era literário - seções "Chronica Semanal", "Contos Ilustrados", "Escriptores e Livros" - e ora era opinativo".

$\mathrm{Na}$ bibliografia internacional, há vestígios da nomenclatura “periodismo de variedades” em artigo de Jesús Costa (1998, p.45, tradução nossa), que trata sobre a ligação de escritores espanhóis com a "dimensão lúdica" do jornalismo ${ }^{17}$. Ele entende que o jornalismo de variedades, mesmo com sua característica de diversão, possibilita a alguns jornalistas "transmitir ideias sérias a seus leitores", mesmo em assuntos considerados menos relevantes, como moda ou tendências; além disso, o autor afirma que é tal espaço da imprensa é ideal para que intelectuais possam tratar temas políticos de maneira satírica, sem, com isso, ser vulgar ou nem um pouco reflexivo.

Se não é comum encontrar a expressão "jornalismo de variedades”, também não é tão fácil localizar referências que adotam o termo "jornalismo de entretenimento", "representado pelas matérias recreativas (passatempos, tiras, features etc.)” (RABAÇA; BARBOSA, 2001, p.405). E a dificuldade que há para encontrá-los talvez seja resultado do próprio embate conceitual que muitos autores provocam - como ocorre com o verbete aqui citado, que consta no Dicionário de Comunicação - ao amalgamar as informações trabalhadas jornalisticamente - no caso, os features - com os componentes que em nada correspondem ao jornalismo - os passatempos e as tiras, entre outros exemplos. Por isso mesmo, Michael Kunczik (2002, p.105) adverte que definir o entretenimento no contexto jornalístico é exercício dos mais difíceis.

\footnotetext{
${ }^{16}$ A questão dos espaços destinados à opinião na revista Fon-Fon não aparece muito claramente no texto de Gottardi e Nahes (2006, p.196). As autoras afirmam que a revista, "por meio de fotos, publicidade e super-adjetivação, emite a 'sua opinião', que é a mesma do Estado, sobre acontecimentos, quaisquer que sejam". Nesse sentido, elas não delimitam as fronteiras que separam o conteúdo jornalístico do material publicitário, problema semelhante ao que foi identificado em outros textos anteriormente mencionados.

${ }^{17}$ Vale acrescentar que, em seu artigo, Jesús Costa não faz diferenças entre textos caracteristicamente jornalísticos e textos literários que esses escritores porventura possam publicar nas páginas dos jornais. $\mathrm{O}$ autor, inclusive, cita exemplos das duas naturezas.
} 
Leandro Marshall (2003, p.27) identifica essa junção como tendência desencadeada nos Estados Unidos, durante a década de 1980, e que já se tornou predominante em muitos cenários. Esse novo modelo ${ }^{18}$ indica que "a cobertura das notícias mais sérias, que exige maior investigação e maior profundidade, foi trocada por notícias de entretenimento, que têm maior efeito sobre a audiência e custam bem menos à empresa"; nesse contexto, aliás, a informação trabalhada jornalisticamente tem menor peso do que as imagens, do que os recursos gráficos coloridos e até mesmo do que a própria diagramação dos veículos impressos. Em contrapartida, Marques de Melo (2009c, p.95) chama a atenção para o fato de que esse fenômeno comporta duas dimensões: a primeira é relacionada ao "entretenimento enquanto 'conteúdo' jornalístico”, ou seja, às matérias a respeito do show business, do mundo das celebridades e de assuntos similares; a segunda pressupõe o entretenimento "enquanto 'gênero' jornalístico”, formado por "textos leves e bem escritos, geralmente mimetizando o estilo literário, produzido com a finalidade de ocupar os espaços ociosos dos leitores mais sensíveis e exigentes".

Recentemente, a revista Estudos em Jornalismo e Midia, da Universidade Federal de Santa Catarina (UFSC), dedicou uma edição inteira a reflexões em torno da tríade informação, entretenimento e espetacularização. No texto que abre o núcleo temático daquele número, a editora Gislene Silva (2008, p.5) assegura que colocar esses terrenos em confronto é uma tendência comum nas pesquisas da área.

Essa função de entretenimento atribuída ao jornalismo é, certamente, característica "da civilização pós-industrial” ${ }^{19}$, como foi mencionado anteriormente. Luiz Amaral (1982, p.21), amparado pelas reflexões do sociólogo Jean Stoetzel, considera que a

\footnotetext{
${ }^{18}$ A esse modelo, feito para agradar a todos - "usuário, consumidor, cliente, dono, anunciante etc." -, Marshall (2003, p.27) atribui o nome de "jornalismo cor-derosa”, termo criado pelo jornalista norte-americano Howard Kurtz.

${ }^{19}$ A expressão "sociedade pós-industrial” foi cunhada, na década de 1960, pelo sociólogo estadunidense Daniel Bell, que presidia a "Comissão para o ano 2000", instituída pela Academia Americana de Artes e Ciências, a fim de discutir questões acerca do futuro (BELTRÃO; QUIRINO, 1986, p.34).
} 
“recreação" é "a segunda função psicossocial da imprensa” e que o público inserido nesse cenário faz da própria leitura do jornal uma "atividade de prazer". Como complemento a essa discussão, Kunczik (2002, p.106) adverte que "a separação entre informação e entretenimento, que ainda existe nos organogramas de muitas empresas dos meios de comunicação, não tem nenhum sentido para os receptores".

\section{Breve conclusão}

Discutir a configuração do jornalismo de variedades exige, inevitavelmente, associá-lo às transformações às quais o próprio jornalismo foi submetido ao longo dos tempos. Não é possível deixar de lado o fato de que o mercado, cada vez mais, busca transformar a imprensa em produto mais agradável. Sem entrar no mérito da relevância dessa metamorfose, bem como dos abalos que ela pode provocar nas estruturas da atividade jornalística, é fato comprovado que a cobertura que os veículos midiáticos fazem sobre os bens simbólicos não é igual à que se fazia no século passado - ou antes disso -, quando a elite intelectual dominava essas seções.

Percebe-se, então, que, ao ser reinventado, o jornalismo cultural abriu mais espaço para o jornalismo de variedades. Não se trata de um subproduto, mas, sim, da evolução de uma prática antiga. Ao longo da revisão bibliográfica aqui apresentada, procurou-se deixar claro que as variedades não foram apropriadas pela imprensa somente no declínio do século 20 ou no amanhecer do século 21. Há muito, a imprensa reserva-se também ao entretenimento. Ocorre, todavia, que o cenário evoluiu. Antigamente, eram os folhetins que se destinam ao divertimento do leitor; hoje, eles foram substituídos por conteúdos que ora despertam curiosidade - como matérias sobre olimpianos ou sobre os bastidores da telinha -, ora dão dicas sobre o que fazer nos momentos de descanso.

O problema que se identifica, pela bibliografia consultada e pela observação sistemática - ou mesmo cotidiana - de jornais e revistas, é que as variedades ficaram associadas às fofocas, principalmente às que marcam os programas de televisão, costumeiramente exibidos durante a semana, no período da tarde. No entanto, uma coisa 
não diz respeito à outra. Fazendo um comparativo, para esclarecer a questão, não é difícil notar que o jornalismo policial feito de maneira comprometida e atenta aos problemas sociais é bem diferente do jornalismo sensacionalista que explora alguns acontecimentos apenas pelo viés da curiosidade que o fato inusitado pode despertar. Com o entretenimento e o lazer, a regra aparenta ser a mesma. Se existem programas televisivos e radiofônicos destinados somente aos burburinhos formados em torno de celebridades, não quer dizer que toda a programação audiovisual do segmento ou, mais precisamente, as editorias dos jornais impressos precisam ser iguais.

Também é possível afirmar que a prática do jornalismo de variedades está intimamente relacionada à ascensão do show business e à grande oferta de produtos da indústria cultural, que já fazem parte do cotidiano da sociedade. Cada veículo, evidentemente, confere um tipo de tratamento a essa especialidade, conforme seus interesses editoriais.

Em estudo comparativo que elaboramos em 200920, arriscamonos a oferecer um conceito para o jornalismo de variedades, o qual deve ser revisto e confrontado de acordo com o contexto em que for evocado. Em nossa concepção, essa especialidade é direcionada, principalmente, à cobertura de pautas sobre cultura e entretenimento, com enfoque na informação e na orientação a respeito das opções de lazer em que essas esferas podem se constituir; também é prática que dá projeção ao universo midiático e à alta sociedade, com particular atenção a celebridades e a pessoas cujas vidas pessoais despertam interesse e curiosidade nos outros.

Por tudo isso, este artigo reivindica a autonomia do jornalismo de variedades, em razão não apenas de sua forma e de seu conteúdo, como também da relevância social do entretenimento e do divertimento, que, sem dúvida alguma, constituem necessidades humanas.

\footnotetext{
${ }^{20}$ Trata-se da nossa dissertação de mestrado - As variedades no jornalismo brasileiro (ASSIS, 2009) -, defendida e aprovada em 24 de novembro de 2009, na Universidade Metodista de São Paulo (Umesp). Nesse trabalho, identificamos o perfil da editoria de variedades em cinco jornais regionais e em um prestige paper editados no Brasil. A partir de tal análise é que pudemos formular o conceito aqui apresentado.
} 


\section{REFERÊNCIAS}

ABRAMO, Bia. "Tudo a Ver" tem jornalismo de variedades. Folha de S.Paulo, São Paulo, 19 jun. 2005. Ilustrada. Disponível em: < http://www1. folha.uol.com.br/fsp/ilustrad/ fq1906200518.htm >. Acesso em: 15 out. 2008.

ALCÂNTARA, Norma; CHAPARRO Manuel Carlos; GARCIA, Wilson. Imprensa na berlinda: a fonte pergunta. São Paulo: Celebris, 2005.

ALMEIDA, Daniela de Jesus. Do show à notícia: a inclusão do jornalismo nos programas de auditório de variedades. 2004. 126 f. Dissertação (Mestrado em Comunicação Social) - Universidade Metodista de São Paulo, São Bernardo do Campo, 2004.

AMARAL, Luiz. Técnica de jornal e periódico. 3. ed. Fortaleza: Tempo Brasileiro, UFCE, 1982.

ARONCHI DE SOUZA, José Carlos. Gêneros e formatos na televisão brasileira. São Paulo: Summus, 2004.

ASSIS, Francisco de. As variedades no jornalismo brasileiro. 2009. $254 \mathrm{f}$. Dissertação (Mestrado em Comunicação Social) - Universidade Metodista de São Paulo, São Bernardo do Campo, 2009.

BAHIA, Juarez. Jornal, história e técnica: história da imprensa brasileira. vol. 1. 4. ed. São Paulo: Ática, 1990.

BARBOSA FILHO, André. Gêneros radiofônicos: os formatos e os programas em áudio. São Paulo: Paulinas, 2003.

BELTRÃO, Luiz. Teoria e prática do jornalismo. Adamantina: FAI, São Bernardo do Campo: Cátedra Unesco/Metodista de Comunicação para o Desenvolvimento Regional, 2006.

. Jornalismo opinativo. Porto Alegre: Sulina, 1980.

; QUIRINO, Newton de Oliveira. Subsídios para uma teoria da comunicação de massa. São Paulo: Summus, 1986.

BUITONI, Dulcília. Entre o consumo rápido e a permanência: jornalismo de arte e cultura. In: MARTINS, Maria Helena (org.). Outras leituras: televisão, jornalismo de arte e cultura, linguagem integrante. São Paulo: SENAC-SP, 2000, p. 55-72. 
. Mulher de papel: a representação da mulher na imprensa brasileira. São Paulo: Loyola, 1981.

COSTA, Jesús. Periodismo y política: la faceta lúdica de Bécquer, Correa y Ferrán. El Gnomo: Boletín de estudios becquerianos, La Rioja, n. 7, p. 29-52, 1998.

COUTO, José Geraldo. Jornalismo Cultural em crise. In: DINES, Alberto; MALIN, Mauro (orgs.). Jornalismo brasileiro: no caminho das transformações. Brasília: Banco do Brasil, 1996, p. 129-131.

CRUZ, Heloisa de Faria. São Paulo em papel e tinta: periodismo e vida urbana (1890-1915). São Paulo: EDUC, Imprensa Oficial, 2000.

ERBOLATO, Mário L. Jornalismo especializado: emissão de textos no jornalismo impresso. São Paulo: Atlas, 1981.

FARO, J. S. Jornalismo cultural: informação e crítica, mais que entretenimento. Estudos de Jornalismo e Relações Públicas: Revista dos cursos de Jornalismo e Relações Públicas da Universidade Metodista de São Paulo, São Bernardo do Campo, n. 9, p. 75-88, 2007.

- Nem tudo o que reluz é ouro: contribuição para uma reflexão teórica sobre o jornalismo cultural. Comunicação $\mathbb{\&}$ Sociedade: Revista do Programa de Pós-Graduação em Comunicação Social da Universidade Metodista de São Paulo, São Bernardo do Campo, ano 28, n. 46, p. 143-163, 2006.

GADINI, Sérgio Luiz. A lógica do entretenimento no jornalismo cultural brasileiro. Epitc On-line: Revista de Economía Política de las Tecnologías de la Información y Comunicación, v. 9, n. 1. jan./abr. 2007. Disponível em: $<$ http://www.eptic.com.br/pdfrevistaIX.n1/9\%20 SergioGadini.pdf > . Acesso em: 10 out. 2007.

A cultura como notícia no jornalismo brasileiro. Rio de Janeiro: Prefeitura da Cidade do Rio de Janeiro, Secretaria Especial de Comunicação Social, 2003.

GARCIA, Maria Cecília. Reflexões sobre a crítica teatral nos jornais: Décio de Almeida Prado e o problema da apreciação da obra artística no jornalismo cultural. São Paulo: Mackenzie, 2004.

GOTTARDI, Ana Maria; NAHES, Semíramis. Revista Fon-Fon: a imagem da mulher no Estado Novo. Comunicação: Veredas, Marília, v. 5, n. 5, p. 189. 204, nov. 2006. 
JANUÁRIO, Marcelo. Olhar superficial: a transformações no jornalismo cultural em São Paulo na passagem para o século XXI. 2005. 243 f. Dissertação (Mestrado em Ciências da Comunicação) - Universidade de São Paulo, 2005.

KUNCZIK, Michael. Conceitos de jornalismo: norte e sul. 2. ed. São Paulo: EDUSP, 2002.

MARCONDES FILHO, Ciro. Comunicação e jornalismo: a saga dos cães perdidos. 2. ed. São Paulo: Hacker, 2002.

MARQUES DE MELO, José. Gêneros jornalísticos no Brasil: o estado da questão. In: Congresso Brasileiro de Ciências da Comunicação, 32., Curitiba, 2009. Anais eletrônicos... São Paulo: Intercom, 2009a.

. Jornalismo: compreensão e reinvenção. São Paulo: Saraiva, 2009 b.

. Jornalismo, forma e conteúdo. São Caetano do Sul: Difusão, 2009c.

. História social da imprensa: fatores socioculturais que retardaram a implantação da imprensa no Brasil. Porto Alegre: EDIPUCRS, 2003.

. Estudos de jornalismo comparado. São Paulo: Livraria Pioneira, 1972.

MARSHALL, Leandro. O jornalismo na era da publicidade. São Paulo: Summus, 2003.

MARTINS, Ana Luiza. Revistas em revista: imprensa e práticas culturais em tempos de república, São Paulo (1890-1922). São Paulo: EDUSP, FAPESP, Imprensa Oficial, 2001.

MCLEISH, Robert. Produção de rádio: um guia abrangente de produção radiofônica. São Paulo: Summus, 2001.

MEDINA, Cremilda. Notícia, um produto à venda: jornalismo na sociedade urbana e industrial. 2. ed. São Paulo: Summus, 1988.

MEYER, Marlyse; DIAS, Vera Santos Dias. Página virada, descartada do meu folhetim. In: AVERBUCK, Ligia (org.). Literatura em tempo de cultura de massa. São Paulo: Nobel, 1984, p. 33-55.

MOCARZEL, Evaldo. Jornalismo especializado em cultura. In: DINES, Alberto (org.). Espaços na mídia: história, cultura e esporte. Brasília: Banco do Brasil, 2001, p. 128-131. 
ORTRIWANO, Gisela Swetlana. A informação no rádio: os grupos de poder e a determinação dos conteúdos. 4. ed. São Paulo: Summus, 1985.

PIZA, Daniel. Jornalismo cultural. 3. ed. São Paulo: Contexto, 2007.

RABAÇA, Carlos Alberto; BARBOSA, Gustavo. Dicionário de Comunicação. 8. ed. Rio de Janeiro: Elsevier, 2001.

RAMONET, Ignacio. A tirania da comunicação. Petrópolis: Vozes, 1999.

RIVERA, Jorge B. El periodismo cultural. Buenos Aires: Paidós, 1995.

SILVA, Gislene. Apresentação. Estudos em jornalismo e mídia, Florianópolis, ano 5, n. 1, p. 5, 1ํㅗ. 2008.

VARGAS, Herom. Reflexões sobre o jornalismo cultural contemporâneo.

Estudos de Jornalismo e Relações Públicas: Revista do curso de Jornalismo e Relações Públicas da Universidade Metodista de São Paulo, São Bernardo do Campo, n. 4, p. 17-25, 2004.

VENTURA, Zuenir. Cadernos culturais. In: RITO, Lúcia; ARAÚJO, Maria Elisa de; ALMEIDA, Candido José Mendes de (orgs.). Imprensa ao vivo. Rio de Janeiro: Rocco, 1989, p. 102-108.

Recebido em: 04/11/2010

Aceito em: 30/03/2011 